\title{
Prevalence and antimicrobial resistance of Campylobacter isolates from poultry offals
}

\author{
BEATA WYSOK, JOANNA WOJTACKA, AGNIESZKA WISZNIEWSKA-ŁASZCZYCH, \\ JOANNA SZTEYN, MAŁGORZATA GOMÓŁKA-PAWLICKA
}

\author{
Department of Veterinary Public Health, Faculty of Veterinary Medicine, \\ University of Warmia and Mazury in Olsztyn, Oczapowskiego 14, 10-917 Olsztyn, Poland
}

\section{Wysok B., Wojtacka J., Wiszniewska-Łaszczych A., Szteyn J., Gomółka-Pawlicka M. Prevalence and antimicrobial resistance of Campylobacter isolates from poultry offals}

\section{Summary}

The aim of the study was to determine the presence of Campylobacter strains in poultry by-products and define antimicrobial resistance of isolates. In total, 400 samples were tested among which 300 included the liver, heart and stomach, and 100 samples represented the contents of the cecum. The samples were taken from chickens and turkeys in the slaughterhouse after evisceration. The prevalence of Campylobacter in chicken samples was $100 \%$ with regards to the contents of cecum and offal. The turkey origin Campylobacter strains were noted in $76 \%$ of the livers, $78 \%$ hearts and $82 \%$ gizzards. The samples of cecum contents were positive in $60 \%$. Species analysis of the strains isolated showed $\mathrm{C}$. jejuni as dominant. The estimation of sensitivity to antibiotics showed that Campylobacter strains were most frequently resistant to quinolones and tetracyclines. Resistance to ciprofloxacin was detected among $52.7 \%$ and $52.5 \%$ chicken and turkey origin strains. The same was noted regarding nalidixic acid, resistance to which was shown in $56 \%$ and $58.5 \%$ isolates, respectively. Regarding tetracyclines, the highest resistance of the strains from chicken and turkey was detected to doxycyclinum in $61.3 \%$ and $53.3 \%$ of isolates, respectively. However the highest sensitivity was showed to erythromycin, gentamicin and chloramphenicol. Only one C. coli strain from turkey offal was resistant to gentamicin. Simultaneously multi drug resistance was defined. The aimed studies showed that $62 \%$ of $C$. jejuni and $53.8 \%$ of $\mathrm{C}$. coli strains from chicken offal were resistant to two or more agents. In turkey origin isolates MDR was detected in $54.7 \%$ of $\mathrm{C}$. jejuni and $53.3 \%$ of $\mathrm{C}$. coli strains.

Keywords: Campylobacter, poultry, offal, contamination, antimicrobial resistance

In recent years, attention has been paid to the growing number of gastrointestinal diseases in humans caused by Campylobacter strains. Poultry plays an important role in transmission of this foodborne pathogen. In particular, chicken and turkey carcasses have been reported to be contaminated with rates up to $100 \%$ and $62.1 \%$, respectively $(16,24)$. Contamination and subsequent colonization of poultry flocks on the farm often lead to transmission of Campylobacter along the whole production chain (19). Contamination of carcasses and internal organs in poultry occur during slaughter and post-slaughter processing (20). People become infected mainly by eating raw or undercooked meat and poultry products. However, the contamination can occur even during handling or preparation of raw meat. Horrocks et al. (11) and Frederick and Huda (9) point out that not only poultry meat, but also by-products represent important sources of food poisoning microorganisms such as Campylobacter spp., Salmonella spp. and
Listeria spp. The infective dose required to cause illness is as low as 500 organisms (10). Therefore, human infections occur relatively easily and often. The report of the European Food Safety Authority (EFSA) shows, that the number of confirmed cases of human campylobacteriosis in 2015 was 229213 with a notification rate of 65.5 per 100000 population (7). Campylobacter infects the small intestine and colon, causing an illness generally characterized by diarrhea, abdominal cramps and fever (12). Symptoms of campylobacteriosis are usually limited and disappear within 3-10 days. Most cases do not require special treatment except from replenishing fluids and electrolytes. However, antibiotic treatment is recommended in case of longterm, severe diarrhea, high fever and confirmation of the presence of Campylobacter spp. in the blood. In terms of the widespread use of antibiotics in animal production, it is necessary to be aware of the increasing number of strains resistant to chemotherapy. The 
problem of Campylobacter resistance to commonly used antibiotics affects not only public health but also animal husbandry and emerges as a global problem (15). It is worth noting that in $201531.2 \%$ infected persons required hospitalization due to Campylobacter infections, and the mortality rate reached $0.03 \%$ (7).

The aim of the present work was to determine the presence of Campylobacter strains in poultry byproducts and define antimicrobial resistance of isolates.

\section{Material and methods}

Bacterial isolation. Material consisted of both internal organs (liver, heart and gizzard) and ceca contents, collected in the chicken and turkey abattoir after evisceration. A total of 400 samples were analyzed. From chickens, 50 samples of ceca, livers, hearts and gizzards were obtained. The same amount of samples were taken from turkeys. Cecum and offals were collected from the same carcasses. Collected byproducts were not subjected to any technological processes. Each sample was put in a sterile bag and transported to the laboratory in a bag with a cooling pack. Then the samples were homogenized and $10 \mathrm{~g}$ of each homogenized sample was placed in stomacher bag with $90 \mathrm{ml}$ buffered peptone water and mixed for 2 minutes in stomacher in order to prepare 10 -fold dilutions. Aliquots $(0.1 \mathrm{ml})$ of these dilutions were spread onto Karmali agar (Oxoid) and mCCDA (charcoal cefoperazone deoxycholate modified agar, Oxoid). After incubation at $42^{\circ} \mathrm{C}$ for $24-48 \mathrm{~h}$ under microaerophilic conditions $\left(5 \% \mathrm{O}_{2}, 10 \% \mathrm{CO}_{2}\right.$ and $\left.85 \% \mathrm{~N}_{2}\right)$, the plates were examined for morphologically typical Campylobacter colonies. Confirmation included microscopic morphology, motility, microaerobic growth at $25^{\circ} \mathrm{C}$ and the presence of oxidase. Campylobacter isolates selected for further analyses were subcultured only once in order to minimize cultural changes and then stored at $-80^{\circ} \mathrm{C}$ in defibrinated horse blood (Oxoid) with the addition of glycerol (80: $20 \mathrm{v} / \mathrm{v})$.

Identification. Identification of species of Campylobacter isolates was carried out using PCR method. Bacteria grown on agar medium were suspended in $1 \mathrm{ml}$ of redistilled water and centrifuged at $13000 \times \mathrm{g}$ for 1 minute. The precipitate was suspended in $100 \mu 1$ of Tris buffer, and then DNA was isolated with the use of Genomic Mini Kit (A\&A Biotechnology), according to the manufacturer's instruction. Purity and concentration of DNA obtained was determined spectrophotometrically; next, after appropriate dilution, it was used for the PCR assays. The primers enabling amplification of gene fragments mapA (specific for C. jejuni), ceuE (the sequence characteristic for C. coli) and $16 \mathrm{~S}$ rRNA (specific for Campylobacter spp.) were used. The sequence of the primers used for amplification are shown in Table 1.

Amplification was performed in a reaction mixture containing: $5 \mu \mathrm{l}$ of enzymatic buffer, $5 \mu 1$ of dNTPs (final concentration $200 \mathrm{mM}), 0.5 \mathrm{ml}$ of each primer (final concentration $0.1 \mathrm{mM}), 10 \mu 1(5 \mathrm{mM})$ of $\mathrm{MgCl}_{2}, 2 \mu \mathrm{l}$ of the thermostable Taq polymerase, $5 \mu$ of template DNA and deionized water free of DNA and RNA to a final volume of $50 \mu 1$. All PCR reactions were carried out using the following parameters: initial denaturation at $94^{\circ} \mathrm{C}$ for $5 \mathrm{~min}$., then 30 cycles: denaturation for $1 \mathrm{~min}$. at $95^{\circ} \mathrm{C}$, primers annealing for $1 \mathrm{~min}$ at the temperature appropriate for a given primer pair, the strand elongation for $1 \mathrm{~min}$. at $72^{\circ} \mathrm{C}$. The final elongation step was carried out at $72^{\circ} \mathrm{C}$ for $5 \mathrm{~min}$. The resulting amplification products were identified on $2 \%$ agarose gel stained with ethidium bromide at a concentration of $5 \mu \mathrm{g} / \mathrm{ml}$. The size of the amplification products obtained were compared with the $100 \mathrm{bp}$ molecular weight marker.

Antimicrobial resistance. Disc diffusion methodology based on the National Committee for Clinical Laboratory Standards (NCCLS) was used in the study. The disc content was as follows: ampicillin $(10 \mu \mathrm{g})$, chloramphenicol $(30 \mu \mathrm{g})$, ciprofloxacin $(5 \mu \mathrm{g})$, doxycycline $(30 \mu \mathrm{g})$, erythromycin $(15 \mu \mathrm{g})$, gentamicin $(10 \mu \mathrm{g})$, nalidixic acid $(30 \mu \mathrm{g})$, streptomycin $(10 \mu \mathrm{g})$ and tetracycline $(30 \mu \mathrm{g})$. In order to obtain pure culture, each selected Campylobacter spp. colony was suspended in Brucella broth so as to obtain a suspension with a density of $1.0 \mathrm{McF}$ arland. The resulting culture was spread on the surface of Mueller-Hinton agar supplemented with 5\% sheep blood and then antibiotic-impregnated discs were applied. The plates were incubated at $37^{\circ} \mathrm{C}$ for $44-48 \mathrm{~h}$ in microaerophilic atmosphere. After incubation, the zone of inhibition was read.

Statistical analysis. Statistical differences in the presence of Campylobacter strains isolated from poultry offals were determined with the use of Tukey test (Statistica, Poland). Chi-square test (Statistica, Poland) was used to determine statistical differences in the presence of antimicrobial resistance. The level of significance was set at $\mathrm{P}<0.05$.

\section{Results and discussion}

Bacterial isolation. Analysis of ceca contents from chicken showed the presence of bacteria from genus Campylobacter in all tested samples, at an average level of $\log 6.23 \mathrm{cfu} / \mathrm{g}$. Simultaneously the contamination of all chicken offals was confirmed and was up to $\log 1.71 \mathrm{cfu} / \mathrm{g}, \log 1.77 \mathrm{cfu} / \mathrm{g}$ and $1.89 \mathrm{cfu} / \mathrm{g}$, in heart, liver and gizzard samples, respectively. While bacteriological examination of ceca contents from turkey indicated the prevalence of Campylobacter spp. at the level $\log 4.56 \mathrm{cfu} / \mathrm{g}$ in 30 of $50(60 \%)$ of the samples analyzed. The prevalence of Campylobacter contamination was detected in $76 \%, 78 \%$ and $82 \%$ of livers, hearts and gizzards, respectively. The contamination was at an average level of $1.01 \log \mathrm{cfu} / \mathrm{g}$ in liver to

Tab. 1. Primers used in PCR assay for identification of Campylobacter spp.

\begin{tabular}{|l|l|c|c|c|}
\hline \multicolumn{1}{|c|}{ rget Gene } & \multicolumn{1}{|c|}{ Sequences (5'-3') } & $\begin{array}{c}\text { PCR product } \\
\text { size (bp) }\end{array}$ & $\begin{array}{c}\text { Annealing } \\
\text { temperature ('C) }\end{array}$ & References \\
\hline $\begin{array}{l}\text { 16S rRNA for } \\
\text { Campylobacter spp. }\end{array}$ & $\begin{array}{l}\text { F-ATCTAATGGCTTAACCATTAAAC } \\
\text { R-GGACGGTAACTAGTTTAGTATT }\end{array}$ & 857 & 58 & Begum et al. (3) \\
mapa for C. jejuni & $\begin{array}{l}\text { F- CTATTTTATTTTTGAGTGCTTGTG } \\
\text { R-GCTTTATTTGCCATTTGTTTATTA }\end{array}$ & 589 & 58 & Begum et al. (3) \\
\hline ceuE for C. coli & $\begin{array}{l}\text { F- AATTGAAAATTGCTCCAACTATG } \\
\text { R- TGATTTTATTATTTGTAGCAGCG }\end{array}$ & 462 & 58 & Begum et al. (3) \\
\hline
\end{tabular}




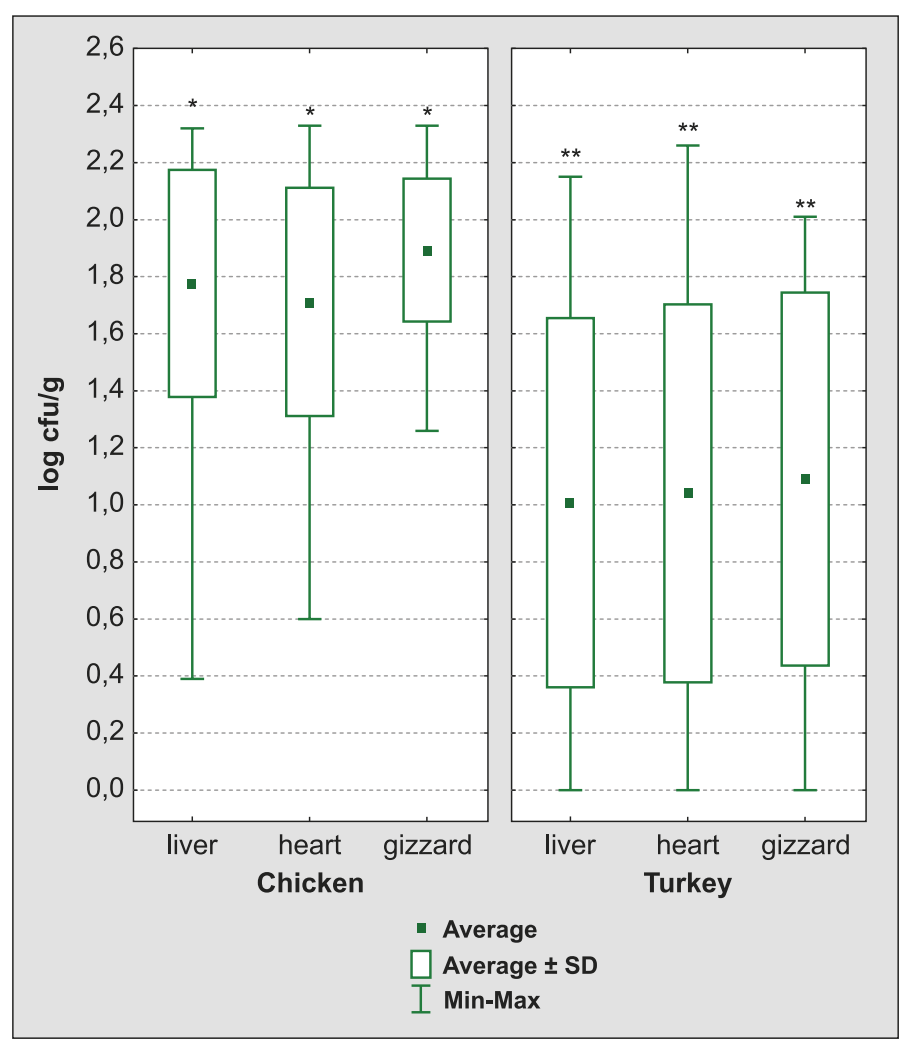

Fig. 1. Number of Campylobacter spp. isolated from chicken and turkey offals

Explanation: Asterisks indicate the significant differences obtained by Tukey test $(\mathrm{P}<0.05)$.

$1.09 \log \mathrm{cfu} / \mathrm{g}$ in gizzard. The incidence rate and the level of Campylobacter contamination of offals between chicken and turkey origin isolates was significantly statistically different $(\mathrm{P}<0.05)$ (Fig. 1 and Fig. 2). Available literature confirms the results obtained. The scientific report of EFSA (5) published in 2010 showed that the mean level of the prevalence of Campylobacter in broiler flocks was $71.2 \%$. However the Member State prevalence varied from $2 \%$ to $100 \%$ for cecal contents. Meade et al. (14) notice that broilers can carry high cecal Campylobacter loads between $10^{6}$ and $10^{8} \mathrm{cfu} / \mathrm{g}$ feces. In turn, among turkey flocks prevalence of Campylobacter is less frequent, about $30 \%$ (18), with contamination levels of ceca ranging from $10^{2}$ to $10^{7} \mathrm{cfu} / \mathrm{g}(4)$. Such a high level of prevalence of Campylobacter in ceca contents lead to contamination of poultry meat. Skarp et al. (19) stress that transport has only a limited effect on the contamination of carcasses, whereas the slaughter process, especially plucking and evisceration, lead to contamination of carcasses and offals.

An equally high level of contamination of chicken livers has been indicated by Wang et al. (22), which confirmed $76 \%$ of samples tested to be Campylobacter positive. Also Fernandez and Pison (8) found Campylobacter in a large number of tested samples of frozen poultry livers. They isolated Campylobacter in $92.9 \%$ of all samples and $C$. coli was dominant (78.6\%) followed by $C$. jejuni in $21.4 \%$ of the samples. However, it was the prevalence of $C$. jejuni that was the highest in the aimed study. It was identified in $90 \%$ of liver samples, while $C$. coli was found in the remaining $10 \%$. More or less positive results have been demonstrated in the research conducted by Atanossova et al. (1), confirming the occurrence of Campylobacter only in $9.7 \%$ of the livers tested, at a level of contamination reaching from $\log 1.6$ to $\log 4.0 \mathrm{cfu} / \mathrm{g}$. In contrast to these results our findings revealed 100\% Campylobacter positive samples of livers, with a contamination rate from 0.39 to $\log 2.26 \mathrm{cfu} / \mathrm{g}$.

The study conducted by Hope et al. (10) points out that consumption of poultry livers can lead to infection due to the potentially high infectious dose of Campylobacter. In addition, these authors oobserved a shorter incubation period in infected people because of high levels of Campylobacter present in livers. Moreover, it should be noted that most of the outbreaks were caused by inadequate cooking of poultry livers $(10,27)$. The internal temperature achieved during preparation of the liver dish was not adequate to kill Campylobacter. Poultry liver should be cooked for 2 to 3 minutes after they reach an internal temperature of $70^{\circ} \mathrm{C}(23)$.

With regard to contamination of heart and gizzard the aimed studies confirmed the prevalence of Campylobacter in 100\% chicken origin offals. Among turkey offals this pathogen was found in $78 \%$ positive heart samples and $82 \%$ positive gizzard samples. Comparing the above results, Bagherpour et al. (2)

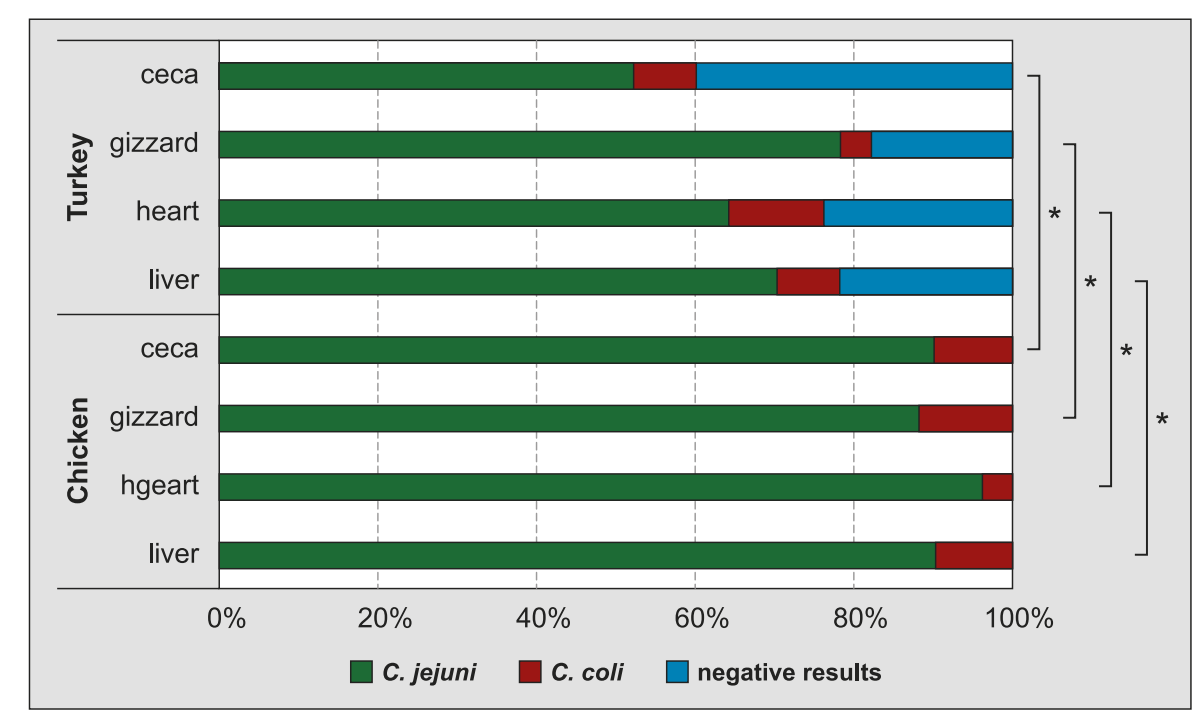

Fig. 2. Prevalence (\%) $C$. jejuni and $C$. coli among chicken and turkey isolates Explanation: Asterisks indicate the significant differences between contamination of chicken and turkey offals and ceca by Campylobacter species obtained by Chi-square test $(\mathrm{P}<0.05)$. 
reported the rate of contamination in $40 \%$ and $45 \%$ of hearts and gizzards, respectively, while Suzuki and Yammamto (21) found the presence of Campylobacter in $62.2 \%$ gizzard and $33.3 \%$ heart samples analyzed.

Obtained differences in the presence of Campylobacter among samples of liver, heart and gizzard may be largely due to varying degrees of contamination of slaughtered poultry, as well as differences in methods of killing or sampling method (2).

Identification. Identification of species of Campylobacter strains showed that $C$. jejuni was dominant (Fig. 2). In regard to 50 Campylobacter isolates from chicken ceca, $45(90 \%)$ were recognized as $C$. jejuni and $5(10 \%)$ as $C$. coli. In turn $C$. jejuni from chicken offals was isolated from $90 \%$ livers, $96 \%$ of hearts and $88 \%$ of gizzards. In relation to the samples taken from turkey $C$. jejuni and $C$. coli were detected in $52 \%$ and $8 \%$ samples of ceca, respectively. Contamination of turkey offals is similar and the results are as follows: $C$. jejuni was detected among 70\%, 64\% and $78 \%$ and C. coli among $10 \%, 12 \%$ and $4 \%$ of livers, hearts and gizzards, respectively. These results correspond with data obtained by other authors, who revealed mostly C. jejuni in the samples obtained from poultry (26). However, the analysis of Campylobacter strains carried out by Wieczorek and Osek (25) showed that the majority were $C$. coli $(58.9 \%)$ positive while $C$. jejuni was detected in the remaining $41.1 \%$ of poultry meat samples. According to Skarp et al. (19) a flock is either colonized by one strain only, which has been
Tab. 2. Prevalence (\%) of antimicrobial resistance among $C$. jejuni and $C$. coli strains from chicken

\begin{tabular}{|c|c|c|c|c|c|c|c|}
\hline \multirow{3}{*}{\multicolumn{2}{|c|}{ Antibiotics }} & \multicolumn{6}{|c|}{ No. of resistant strains (\%) } \\
\hline & & \multicolumn{3}{|c|}{ offals } & \multicolumn{3}{|c|}{ ceca } \\
\hline & & $\begin{array}{l}\text { C. jejuni } \\
(\mathrm{n}=137)\end{array}$ & $\begin{array}{l}\text { C. coli } \\
(n=13)\end{array}$ & $\begin{array}{c}\text { Total } \\
(n=150)\end{array}$ & $\begin{array}{l}\text { C. jejuni } \\
(n=45)\end{array}$ & $\begin{array}{l}\text { C. coli } \\
(\mathrm{n}=5)\end{array}$ & $\begin{array}{c}\text { Total } \\
(n=50)\end{array}$ \\
\hline \multirow{2}{*}{ Quinolones } & Ciprofloxacin & $\begin{array}{c}74 \\
(54.1 \%)\end{array}$ & $\begin{array}{c}5 \\
(38.5 \%)\end{array}$ & $\begin{array}{c}79 \\
(52.7 \%)\end{array}$ & $\begin{array}{c}24 \\
(52 \%)\end{array}$ & $\begin{array}{c}2 \\
(40 \%)\end{array}$ & $\begin{array}{c}26 \\
(52 \%)\end{array}$ \\
\hline & Nalidixic acid & $\begin{array}{c}78 \\
(56.3 \%)\end{array}$ & $\begin{array}{c}6 \\
(46.1 \%)\end{array}$ & $\begin{array}{c}84 \\
(56 \%)\end{array}$ & $\begin{array}{c}23 \\
(51.1 \%)\end{array}$ & $\begin{array}{c}2 \\
(40 \%)\end{array}$ & $\begin{array}{c}25 \\
(\mathbf{5 0} \%)\end{array}$ \\
\hline \multirow{2}{*}{ Tetracyclines } & Tetracycline & $\begin{array}{c}37 \\
(27 \%)\end{array}$ & $\begin{array}{c}3 \\
(23 \%)\end{array}$ & $\begin{array}{c}40 \\
(26.7 \%)\end{array}$ & $\begin{array}{c}12 \\
(26.6 \%)\end{array}$ & $\begin{array}{c}1 \\
(20 \%)\end{array}$ & $\begin{array}{c}13 \\
(26 \%)\end{array}$ \\
\hline & Doksycyclinum & $\begin{array}{c}83 \\
(60.5 \%)\end{array}$ & $\begin{array}{c}9 \\
(69.2 \%)\end{array}$ & $\begin{array}{c}92 \\
(61.3 \%)\end{array}$ & $\begin{array}{c}27 \\
(60 \%)\end{array}$ & $\begin{array}{c}3 \\
(60 \%)\end{array}$ & $\begin{array}{c}30 \\
(60 \%)\end{array}$ \\
\hline Macrolides & Erythromycin & 0 & 0 & 0 & 0 & 0 & 0 \\
\hline \multirow[b]{2}{*}{ Aminoglicosides } & Gentamicin & 0 & 0 & 0 & 0 & 0 & 0 \\
\hline & Streptomycin & $\begin{array}{c}17 \\
(12.4 \%)\end{array}$ & $\begin{array}{c}1 \\
(7.7 \%)\end{array}$ & $\begin{array}{c}18 \\
(12 \%)\end{array}$ & $\begin{array}{c}6 \\
(13.3 \%)\end{array}$ & $\begin{array}{c}1 \\
(20 \%)\end{array}$ & $\begin{array}{c}7 \\
(14 \%)\end{array}$ \\
\hline Amphenicols & Chloramphenicol & 0 & 0 & 0 & 0 & 0 & 0 \\
\hline$\beta$-lactam antibiotics & Ampicillin & $\begin{array}{c}41 \\
(29.9 \%)\end{array}$ & $\begin{array}{c}3 \\
(23 \%)\end{array}$ & $\begin{array}{c}44 \\
(29.3 \%)\end{array}$ & $\begin{array}{c}13 \\
(28.9 \%)\end{array}$ & $\begin{array}{c}1 \\
(20 \%)\end{array}$ & $\begin{array}{c}14 \\
(28 \%)\end{array}$ \\
\hline
\end{tabular}

Tab. 3. Prevalence (\%) of antimicrobial resistance among $C$. jejuni and $C$. coli strains from turkey

\begin{tabular}{|c|c|c|c|c|c|c|c|}
\hline \multirow{3}{*}{\multicolumn{2}{|c|}{ Antibiotics }} & \multicolumn{6}{|c|}{ No. of resistant strains (\%) } \\
\hline & & \multicolumn{3}{|c|}{ offals } & \multicolumn{3}{|c|}{ ceca } \\
\hline & & $\begin{array}{r}\text { C. jejuni } \\
(\mathrm{n}=106)\end{array}$ & $\begin{array}{l}\text { C. coli } \\
(\mathrm{n}=12)\end{array}$ & $\begin{array}{c}\text { Total } \\
(n=118)\end{array}$ & $\begin{array}{l}\text { C. jejuni } \\
(\mathrm{n}=26)\end{array}$ & $\begin{array}{l}\text { C. coli } \\
(\mathrm{n}=4)\end{array}$ & $\begin{array}{l}\text { Total } \\
(n=30)\end{array}$ \\
\hline \multirow{2}{*}{ Quinolones } & Ciprofloxacin & $\begin{array}{c}57 \\
(53.8 \%)\end{array}$ & $\begin{array}{c}5 \\
(41.7 \%)\end{array}$ & $\begin{array}{c}62 \\
(52.5 \%)\end{array}$ & $\begin{array}{c}14 \\
(53.8 \%)\end{array}$ & $\begin{array}{c}2 \\
(50 \%)\end{array}$ & $\begin{array}{c}16 \\
(53.3 \%)\end{array}$ \\
\hline & Nalidixic acid & $\begin{array}{c}64 \\
(60.3 \%)\end{array}$ & $\begin{array}{c}5 \\
(41.7 \%)\end{array}$ & $\begin{array}{c}69 \\
(58.5 \%)\end{array}$ & $\begin{array}{c}16 \\
(61.5 \%)\end{array}$ & $\begin{array}{c}2 \\
(50 \%)\end{array}$ & $\begin{array}{c}18 \\
(60 \%)\end{array}$ \\
\hline \multirow{2}{*}{ Tetracyclines } & Tetracycline & $\begin{array}{c}44 \\
(41.5 \%)\end{array}$ & $\begin{array}{c}4 \\
(33.3 \%)\end{array}$ & $\begin{array}{c}48 \\
(40.7 \%)\end{array}$ & $\begin{array}{c}11 \\
(42.3 \%)\end{array}$ & $\begin{array}{c}1 \\
(25 \%)\end{array}$ & $\begin{array}{c}12 \\
(40 \%)\end{array}$ \\
\hline & Doksycyclinum & $\begin{array}{c}56 \\
(52.8 \%)\end{array}$ & $\begin{array}{c}7 \\
(58.3 \%)\end{array}$ & $\begin{array}{c}63 \\
(53.3 \%)\end{array}$ & $\begin{array}{c}14 \\
(53.8 \%)\end{array}$ & $\begin{array}{c}2 \\
(50 \%)\end{array}$ & $\begin{array}{c}16 \\
(53.3 \%)\end{array}$ \\
\hline Macrolides & Erythromycin & 0 & 0 & 0 & 0 & 0 & 0 \\
\hline \multirow{2}{*}{ Aminoglicosides } & Gentamicin & 0 & $\begin{array}{c}1 \\
(8.3 \%)\end{array}$ & $\begin{array}{c}1 \\
(0.8 \%)\end{array}$ & 0 & $\begin{array}{c}1 \\
(25 \%)\end{array}$ & $\begin{array}{c}1 \\
(3.3 \%)\end{array}$ \\
\hline & Streptomycin & $\begin{array}{c}14 \\
(13.2 \%)\end{array}$ & 0 & $\begin{array}{c}14 \\
(11.9 \%)\end{array}$ & $\begin{array}{c}4 \\
(15.4 \%)\end{array}$ & 0 & $\begin{array}{c}4 \\
(13.3 \%)\end{array}$ \\
\hline Amphenicols & Chloramphenicol & 0 & 0 & 0 & 0 & 0 & 0 \\
\hline$\beta$-lactam antibiotics & Ampicillin & $\begin{array}{c}28 \\
(26.4 \%)\end{array}$ & $\begin{array}{c}3 \\
(25 \%)\end{array}$ & $\begin{array}{c}31 \\
(26.3 \%)\end{array}$ & $\begin{array}{c}7 \\
(26.9 \%)\end{array}$ & $\begin{array}{c}1 \\
(25 \%)\end{array}$ & $\begin{array}{c}8 \\
(26.7 \%)\end{array}$ \\
\hline
\end{tabular}


biotic in animals destined for food production because of the lack of a safe level of residues and associated inability to determine the withdrawal period. The susceptibility of all analyzed strains to erythromycin was confirmed in the studies conducted by Wieczorek (24). The results published by Rożynek et al. (17) and Woźniak and Wieliczko (26) also showed low resistance levels, not exceeding $1 \%$ to macrolides that are usually used to treat severe infections caused by Campylobacter spp.

Not only macrolides, but also quinolones, such as ciprofloxacin and nalidixic acid, are the primary antimicrobials used for the treatment of human Campylobacter infections (19). However, the pertinent studies have shown the resistance to ciprofloxacin in $52.7 \%$ chicken and $52.5 \%$ turkey isolates from offals. Whereas $56.0 \%$ and $58.5 \%$ of chicken and turkey isolates were resistant to nalidixic acid, respectively. Nevertheless, higher levels of resistance shown for C. jejuni than C. coli isolates did not result in statistically significant differences $(\mathrm{P}>0.05)$. According to Wieczorek and Osek (25) resistance to quinolones requires only one point mutation in the gyrA gene and has increased rapidly among chicken and human Campylobacter isolates since the early 1990s. These high resistance rates may also be explained by the allowance of quinolones for therapeutic use in veterinary practice in Poland (24).

Tetracyclines are broad-spectrum agents, which exhibit their activity against a wide range of bacteria. Therefore, they have been extensively used in the therapy of human and animal infections. In the recent years the decreasing sensitivity of bacteria to these agents has been observed. In the aimed study the resistance rates to tetracycline and doxycyclinum among Campylobacter isolates from chicken offals were $26.7 \%$ (27.0\% for $C$. jejuni and $23.0 \%$ for C. coli) and $61.3 \%$ (60.5\% for C. jejuni and $69.2 \%$ for C. coli), respectively. Moreover, it was similar among $C$. jejuni and $C$. coli $(\mathrm{P}>0.05)$. Among turkey origin strains from offals $41.5 \%$ C. jejuni and $33.3 \%$ C. coli shown to be resistant to tetracycline. Doxycyclinum resistant isolates were $52.8 \%$ of $C$. jejuni and $58.3 \%$ of $C$. coli strains. Altogether the resistance level of Campylobacter strains was $40.7 \%$ and $53.3 \%$ to tetracycline and doxycyclinum, respectively. A slightly higher resistance rate to tetracycline was observed by Maćkiw et al. (13), who demonstrated 64.3\% resistant Campylobacter strains, including $62 \%$ for $C$. coli and $71.4 \%$ for $C$. jejuni. Moreover, the European Union Summary report on antimicrobial resistance points to significant differences in resistance among $C$. coli and $C$. jejuni strains, reaching up to $36.3 \%$ and $73.9 \%$, respectively (6).

High efficiency has been confirmed to aminoglicosides, in this way underlining their importance in reduction of Campylobacter infections. All Campylobacter strains isolated from chicken offals were susceptible to gentamicin. Among the strains of turkey origin from offals, only one isolate $(0.8 \%)$ was resistant to this agent. On the other hand, relatively low resistance of Campylobacter strains to streptomycin was noted. In broilers $12.4 \%$ of $C$. jejuni and $7.7 \%$ of $C$. coli isolates were resistant to this agent. Among turkey origin strains only $C$. jejuni isolates were resistant to streptomycin, showing resistance level of $11.9 \%$. High sensitivity of bacteria from genus Campylobacter to aminoglicosides was showed in the studies conducted by other authors $(13,17,24)$.

A slightly higher resistance level was observed to $\beta$-lactam antibiotics. The respective rates in chicken and turkey isolates from offals were $29.3 \%$ and $26.3 \%$. Rożynek et al. (17) underlined increasing resistance of Campylobacter strains to this agent, noting from 2003 to 2005 , the increase in the number of strains resistance to ampicillin from $5.8 \%$ to $30.4 \%$.

The aimed study revealed that contamination of poultry offals occurs during slaughter processing. To a large extent this is due to the presence of Campylobacter in the digestive tract. The research conducted showed no statistically significant differences $(\mathrm{P}>0.05)$ between resistance of Campylobacter strains isolated from ceca and offals to selected antibiotics. Among chicken isolates from ceca (Tab. 2) no resistance was observed to erythromycin, gentamicin and chloramphenicol. Several strains were resistant to tetracycline (26\%), streptomycin (14\%) and ampicillin $(28 \%)$. The highest levels of resistance was noted to ciprofloxacin (52\%), nalidixic acid (50\%) and doksycyclinum $(60 \%)$. The result of resistance of turkey isolates from ceca to tested antimicrobials showed that resistance to quinolones and tetracyclines was more frequent (Tab. 3). All of the isolates were susceptible to erythromycin and chloramphenicol.

Many authors stress an emerging trend of the growth of the number of multi-resistance strains $(24,26)$. The authors' studies showed that $62 \% C$. jejuni and $53.8 \%$ C. coli strains from chicken offals were resistant to two or more classes of antibiotics. Regarding turkey origin isolates, multi-resistance was detected in $54.7 \%$ C. jejuni and $53.3 \%$ C. coli strains. Woźniak and Wieliczko (26) stress that the broad usage of chemotherapy in poultry and increasing use of antibiotics in human medicine contribute to the increase in the percentage of the strains resistant to one or several chemotherapeuticals.

The results obtained showed a high level of Campylobacter contamination from $78 \%$ positive heart samples of turkey origin to $100 \%$ positive of all chicken offals. The highest levels rate were $\log 2.26 \mathrm{cfu} / \mathrm{g}$ and $\log 2.33 \mathrm{cfu} / \mathrm{g}$ in turkey and chicken offals, respectively. Moreover, evaluation of antimicrobial resistance showed macrolides and aminoglicosides to be the first choice antibiotics in treatment of campylobacteriosis.

In conclusion, it should be noted that the consumption of raw or heat-treated at low temperatures 
poultry meat or by-products can have a significant risk of Campylobacter infections. Poultry offals such as liver, heart and gizzard have many fans among various classes of society due to their low prices, high nutritional value and different and favorite tastes (2). Therefore, the microbiological quality of poultry products is crucial. Cross-contamination of the surface of by-products during processing by contents from the intestines is significant with respect to Campylobacter counts obtained from offal samples.

\section{References}

1. Atanassova V., Reich F., Beckmann L., Klein G.: Prevalence of Campylobacter spp. in turkey meat from a slaughterhouse and in turkey meat retail products. FEMS Immunol. Med. Microbiol. 2007, 49, 141-145.

2. Bagherpour A.: Survey of Campylobacter contamination in poultry meat and by-products in Dezful province. WALIA J. 2014, 30, 115-431.

3. Begum S., Sekar M., Gunaseelan L., Gawande M., Suganya G., Annal Selva Malar P., Karthikeyan A.: Molecular identification of Campylobacter jejuni and coli from chicken, calves and dogs to determine its potential threat on human being. Vet. World 2015, 12, 1420-1423.

4. Bily L., Petton J., Lalande F., Rouxel S., Denis M., Chemaly M., Salvat G., Fravalo P.: Quantitative and qualitative evaluation of Campylobacter spp. contamination of turkey cecal contents and carcasses during and following the slaughtering process. J. Food. Prot. 2010, 73, 1212-1218.

5. European Food Safety Authority (EFSA): Analysis of the baseline survey on the prevalence of Campylobacter in broiler batches and of Campylobacter and Salmonella on broiler carcasses in the EU, 2008 - Part A: Campylobacter and Salmonella prevalence estimates. EFSA J. 2010, 8, 1522

6. European Food Safety Authority (EFSA): The European Union Summary report on antimicrobial resistance in zoonotic and indicator bacteria from humans, animals and food in 2014. EFSA J. 2016, 14, 4380.

7. European Food Safety Authority (EFSA): The European Union Summary report on trends and sources of zoonoses, zoonotic agents and food - borne outbreaks in 2015. EFSA J. 2016, 14, 4634

8. Fernandez H., Pison V.: Isolation of thermotolerant species of Campylobacter from commercial chicken livers. Int. J. Food Microbiol. 1996, 29, 75-80.

9. Frederick A., Huda N.: Campylobacter in poultry: Incidences and possible control measures. Res. J. Microbiol. 2011, 6, 182-192.

10. Hope K. G., Merritt T. D., Durrheim D. D.: Short incubation periods in Campylobacter outbreaks associated with poultry liver dishes. Commun. Dis. Intell. Q. Rep. 2014, 38, 20-23.

11. Horrocks S. M., Anderson R. C., Nisbet D. J., Ricke S. C.: Incidence and ecology of Campylobacter jejuni and coli in animals. Anaerobe 2009, 15 $18-25$
12. Kirkpatrick B. D., Tribble D. R.: Update on human Campylobacter jejuni infections. Curr. Opin. Gastroenterol. 2011, 27, 1-7.

13. Maćkiw E., Korsak D., Rzewuska K., Tomczuk K., Rożynek E.: Antibiotic resistance in Campylobacter jejuni and Campylobacter coli isolated from food in Poland. Food Control 2012, 23, 297-301.

14. Meade K. G., Narciandi F., Cahalane $S$, Reiman C., Allan B., O'Farrelly $C$. Comparative in vivo infection models yield insights on early host immune response to Campylobacter in chickens. Immunogenetics 2009, 61, 101-110.

15. Molla B., Mesfin A., Alemayehu D.: Multiple antimicrobial - resistant Salmonella serotypes isolated from chicken carcasses and giblets in Debre Zeit and Addis Ababa, Ethiopia. Ethiop. J. Health. Dev. 2003, 17, 131-149.

16. Rahimi E., Momtaz H., Bonyadian M.: PCR detection of Campylobacter sp. from turkey carcasses during processing plant in Iran. Food Control 2010, 21, 692-694.

17. Rożynek E., Dzierzanowska-Fangrat K., Korsak D., Konieczny P., Wardak S. Szych J., Jarosz M., Dzierzanowska D.: Comparison of antimicrobial resistance of Campylobacter jejuni and Campylobacter coli isolated from humans and chicken carcasses in Poland. J. Food Protect. 2008, 71, 602-607.

18. Scupham A. J.: Campylobacter colonization of the turkey intestine in the context of microbial community development. Appl. Environ. Microbiol. 2009, 75, 3564-3571.

19. Skarp C. P. A., Hanninen M.-L., Rautelin H. I. K.: Campylobacteriosis: the role of poultry meat. Clin. Microbiol. Infect. 2016, 22, 103-109.

20. Smith D. P., Berrang M. E.: Prevalence and numbers of bacterial in broiler crop and gizzard contents. Poult. Sci. 2006, 85, 144-147.

21. Suzuki H., Yamamoto S.: Campylobacter contamination in retail poultry meats and by-products in Japan. J. Vet. Med. Sci. 2009, 71, 255-261.

22. Wang X., Zha S., Harbottle H., Tran T., Blickenstaff K., Abbott J., Meng J. Antimicrobial resistance and molecular subtyping of Campylobacter jejuni and Campylobacter coli from retail meats. J. Food Protect. 2011, 74, 616-662.

23. Whyte R., Hudson J., Graham C.: Campylobacter in chicken livers and their destruction by pan frying. Lett. Appl. Microbiol. 2006, 43, 591-595.

24. Wieczorek K.:Antimicrobial resistance and virulence markers of Campylobacter jejuni and Campylobacter coli isolated from retail poultry meat in Poland. Bull. Vet. Inst. Pulawy 2010, 54, 563-569.

25. Wieczorek K., Osek J.: Antimicrobial resistance mechanisms among Campylobacter. BioMed. Res. Int. 2013, 2013, 340-605

26. WoźniakA., Wieliczko A.: Tetracycline, erythromycin and gentamicin resistance of Campylobacter jejuni and Campylobacter colinisolated from poultry in Poland. Bull. Vet. Inst. Pulawy 2011, 55, 51-54.

27. Young N. J., Day J., Montsho-Hammond F., Verlander N. Q., Irish C., Panhania B., Oliver I.: Campylobacter infection associated with consumption of duck liver pate: a retrospective cohort study in the setting of near universal exposure. Epidemiol. Infect. 2014, 142, 1269-1276.

Corresponding author: Dr Beata Wysok, ul. Oczapowskiego 14, 10-957 Olsztyn; e-mail: bea_wysok@wp.pl 